\title{
Scientific Names: Linking the Past to Provide Context for Knowledge
}

\author{
Thomas M. Orrel| ${ }^{\ddagger}$, David Mitche\|॥§,। \\ ‡ National Museum of Natural History, Smithsonian Institution, Washington, DC, United States of America \\ § Integrated Taxonomic Information System, Washington, DC, United States of America \\ I U.S. Geological Survey, Reston, VA, United States of America
}

Corresponding author: Thomas M. Orrell (orrellt@si.edu), David Mitchell (mitchelld@si.edu)

Received: 31 Jul 2017 | Published: 01 Aug 2017

Citation: Orrell T, Mitchell D (2017) Scientific Names: Linking the Past to Provide Context for Knowledge.

Proceedings of TDWG 1: e19937. https://doi.org/10.3897/tdwgproceedings.1.19937

\section{Abstract}

The Integrated Taxonomic Information System (ITIS - www.itis.gov) maintains a regularly updated database of global scientific names and their hierarchical or synonymic relationships. Containing over 840,000 scientific names, ITIS is an authoritative reference across all seven kingdoms of life and provides a robust structure for organizing biodiversity information. A single taxon may be represented by multiple scientific names, so ITIS makes it a priority to provide synonymy. Linking valid or accepted names with their subjective and objective synonyms is a key component of name translation and for increasing the precision of searches and organization of information. ITIS and partner Species2000 create the Catalogue of Life checklist that provides quality scientific name data for over $1.7 \mathrm{M}$ species. This checklist helps organize the scientific names found in literature which date from as far back as the 1750s. The results of a recent needs analysis is energizing a new ITIS and Species2000 initiative to provide a more complete Catalogue of Life. The focus is on filling known taxonomic gaps and adding missing synonyms in order to provide context for biodiversity knowledge. 


\section{Keywords}

taxonomy, database, scientific names, Catalogue of Life, Integrated Taxonomic Information System

\section{Presenting author}

Thomas M. Orrell 